\title{
Dede Korkut Kitabı ve Kırgız Edebiyatında 'Yahşı/Cakşı’' Redifli Öğüt İfadeleri Üzerine
}

\author{
Dede Korkut Book and The Literature of Kyrgyz 'Yahşi / Cakşi' About Advice \\ Expressions
}

\author{
Doç. Dr. Cüneyt AKIN ${ }^{1}$
}

\begin{abstract}
$\ddot{O} z$
Tarihî ve çağdaş Türk lehçeleri arasında henüz yeni diyebileceğimiz karşılaştırmalı çalışmalar, Türk dili ve edebiyatını daha doğru anlamamızı kolaylaştıracaktır. Ayrıca, Türk dilinin lehçe ve edebiyatlarını mukayese etmek, genel yapıyı kavramamızı, dolayısıyla, Türk dili ve lehçe ve edebiyatları hakkında daha sağlıklı hükümler verebilmemizi sağlayacaktır. Karşılaştırmalı olarak ele aldığımızda, Türk Edebiyatının birtakım eserlerindeki nasihat türü örnekleri üslup ve şekil bakımından bazı ortak özelliklere sahiptir. Türk edebiyatının en önemli eserlerinden biri olan "Kitâb-1 Dedem Korkut", içerisinde nasihat ifade eden örneklerin yer aldığı eserlerden biridir. Bu örneklerden bazıları, çağdaş Türk lehçelerindeki nasihat türü örneklerle üslup ve şekil bakımından örtüşmektedir. Türk Edebiyatında Nasihat türü örneklerinin şekil ve içerik bakımından ortak özelliklerinin ortaya konulmasının, Türk Edebiyatının gelişimini, şekillenişini ve farklı coğrafyalardaki özelliklerini keşfetmek bakımından faydalı olacaktır kanaatindeyiz. Çağdaş Türk Edebiyatında 'Nasihat Türü', Türk lehçelerinin edebiyatlarında görülmektedir. Kırgız Edebiyatında nasihat türünün çok sayıda örneği olduğunu biliyoruz. Bu nasihat türü örnekler, bazı şairlerin eserlerinde müstakil olarak karşımıza çıkar. Örneğin, Tokotogul Satılganuulu'nun Nasihat adı altında bir eseri bulunmaktadır. Ayrıca, Barpı ve Arstanbek Buylaşuulu gibi şairlerin de nasihat içerikli şiirlerine rastlamaktayız. Bundan önceki çalışmalarda, Yunus Emre'nin nasihat içerikli şiirleri, Kırgız Edebiyatı'ndaki çeşitli şâirlerin nasihat içerikli şiirleriyle tematik olarak karşılaştırılmıştı. Ortaya çıkan sonuç, Anadolu ile Türkistan sahası Türk edebi geleneği nasihat geleneğinin önemli ölçüde aynı kaynaklardan beslendiğini ve aynı kökleri işaret ettiğini göstermişti. Bir diğer çalışmada ise, Eski Anadolu Türkçesi dönemine ait ve Türk Edebiyatı en önemli eserlerinin başında yer alan Dede Korkut'taki nasihat içerikli söz kalıplarının, Kırgız Edebiyatı'ndaki nasihat içerikli kalıplarla karşılaştırması yapılmıştır. Söz konusu karşılaştırma neticesinde ortaya, benzer şekillerde ve benzer içeriklerde birtakım söz kalıpları çıkmıştır. Dede Korkut üzerine yapılan çalışmalarda ele alınmayan bu konu, karşılaştırmalı lehçe çalışmaları arasında da yer almamaktadır. Bu nedenlerle çalışma, özgün bir özellik taşımaktadır. Çalışmada aynı zamanda hermeneutik yöntem ve bakış açısı kullanılmış, yapılan değerlendirmeler ahlak felsefesindeki iyi kavramı bağlamından hareketle ortaya konulmuştur.
\end{abstract}

Anahtar Kelimeler: Dede Korkut, Kırgız Edebiyat1, nasihat, hermeneutik

Makale türü: Derleme

\begin{abstract}
The importance of comparative studies between historical and contemporary Turkish dialects is huge. The works we can say new in this area will make Turkish Language and Literature easier to understand. When we consider comparatively, examples of types of advice in some works of Turkish Literature have some common features in style and form. Kitâb-i Dede Korkut, one of the most important works of Turkish Literature, is one of the works we encountered in the types of advice. Some of these examples overlap in style and shape with examples of types of advice in contemporary Turkish dialects. We think that revealing the common features of examples of advice types in the Turkish Literature with regards to their structures and contents will be beneficial to explore the development, formation and of Turkish Literature with its features in different geographies. The type of advice in Contemporary Turkish Literature is seen
\end{abstract}

\footnotetext{
1 Afyon Kocatepe Üniversitesi, Fen Edebiyat Fakültesi, cuneyt.akin@hotmail.com, Orcid ID: https://orcid.org/0000-0002-62307222 .

Atıf için (to cite): Akın, C. (2019). Dede Korkut Kitabı ve Kırgız Edebiyatında 'Yahşı/Cakşı' Redifli Öğüt İfadeleri Üzerine. Afyon Kocatepe Üniversitesi Sosyal Bilimler Dergisi 21(2), 495-499
} 
in the literature of Turkish dialects. We know that in Kyrgyz Literature there are many examples of advice type. This kind of advice comes as a self-confident in the works of some poets. For example, there is a work under the title Nasihat of Tokotogul Satılganuulu. We also find poetry poems by poets such as Barpi and Arstanbek Buylasuulu. In the previous studies, the poems of Yunus Emre including advices were compared thematically with the various poets' poems including advices in Kirghiz literature. The obtained result showed that the tradition of advice of Anatolia and Middle Asia has been nourished considerably from the same sources and has indicated the same roots. In another study, a comparison was made between word structures having advice theme of Dede Korkut belonging to the Ancient Anatoliant Turkish and at the top of the most important works of the Turkish Literature, and structures having advice theme in Kirghiz Literature. As a result of this comparison, some word structures were revealed in exactly the same forms and similar contents. Having no place in the studies on Dede Korkut, this issue has not observed in the studies of comparative dialects. For these reasons, this study has a distinctive feature. In the study, at the same time, hermeneutic method and perspective were used, and the evaluations were revealed within the "concept of fine" in the philosophy of ethics.

Keywords: Dada Gorgud, Kirghiz Literature, advice, hermeneutik

Paper type: Review

\section{Giriş}

Arapça nasihat, Farsça pend ve Türkçe öğüt kelimeleri, birbirinin yerine kullanılan kelimelerdir. Sonlarına getirilen Farsça name eki ile, nasihat-name, pend-name ve öğüt-name kavramları türetilmiştir. Literatürde günümüze kadar bu adlarla yazılmış çok sayıda eser bulunmaktadır. Ayrıca, adında nasihat/pend/öğüt/ ifadeleri geçmeyip, içeriğinde nasihat verici unsurların olduğu çok sayıda eser vardır. Türk Edebiyatı'nda bu geleneği Göktürk Abideleri’ne kadar götürebiliriz. Abidelerdeki nasihat niteliğindeki ifadeler, günümüze dahi ışık tutmaktadır. Dîvânu Lugati't-Türk'teki atasözleri, Kutadgu Bilig'te yer alan veciz sözler, Ahmet Yesevî'nin Hikmet'leri, Yunus Emre'nin nasihatleri ve Türk Edebiyatı'nın çok sayıda eseri, nasihat/ögüt/pend içeren ifadelerle örülmüştür. (Ulucan, 2012: 214,223)

Çağdaş Türk Edebiyatında nasihat türü, Türk lehçelerinin edebiyatlarında görülmektedir. Kırgız Edebiyatında nasihat türünün çok sayıda örneği olduğunu biliyoruz. Bu nasihat türü örnekler, bazı şairlerin eserlerinde müstakil olarak karşımıza çıkar. Örneğin, Tokotogul Satılganuulu'nun Nasihat adı altında bir eseri bulunmaktadır. Ayrıca, Barp1 ve Arstanbek Buylaşuulu gibi şairlerin de nasihat içerikli şiirlerine rastlamaktayız. (Akın, 2014: 209,217)

\section{1. 'yahşı (iyi)' Kavramı Üzerine}

Aristocu klasik doğrultudaki felsefe, teorik ve pratik olmak üzere iki ana bölüme ayrılır. Sadece 'bilme' ile ilgili meseleleri konu edinen teorik felsefeye karşıllk pratik felsefe, 'yapma'yı, yani 'eylem'i esas almaktadır. Örneğin, evrenin oluşumu ve maddenin gerçekliği ile ilgili meselelerin, eyleme yönelik herhangi bir etkisi ve neticesi yoktur. Dolayısıly teoriktir. Ancak, 'iyi bir davranışın nasıl olması gerektiği' şeklindeki bir soru, doğrudan eyleme dönüktür. Tek başına 'iyi' kavramının özüne ilişkin bir araştırma dahi, neticede eylemle bağlantısı olduğu için, 'pratik felsefe'ye dâhildir. Ahlak kavramının özü ise, 'olumlu' bir mahiyete sahiptir. İyi ve 'olması gereken' şeyler, ahlakı ifade ederler. Felsefî dilde buna, 'normatif' yani 'buyurucu' özelliğe sahip denilmektedir. Yani 'ahlak', yapılmass gereken davranışların', 'iyi bir insan olmak için gereken 'lerin ilmi olarak anlaşılmasıdır. Bu nedenle, 'nasihat' ve 'âdâb' türündeki eserler, yalnızca erdemlerin sıralandığı ve 'erdemli insan' özelliklerinin anlatıldığı kitaplar, ahlâkî yükümlülüklerin anlatıldığı dinî veya kültürel eserler daha ziyade 'ahlak ilmi' kapsamında değerlendirilmiştir. (Özturan, 2015: 1-2)

Yukarıda bahsedildiği gibi, pratik ahlakın içinde ahlak felsefesinin konularından biri olan iyi (yahşı) kavramı, Türk Edebiyatının 'nasihat' içerikli çok sayıda eserinde bulunmaktadır. Eski Türkçede, Divanu Lugati't-Türk ve Kutadgu Bilig'de 'yahşı' kelimesi, çeşitli fonetik şekillerde karşımıza çıkmaktadır. (Hacızade, 1999: 203-204) 


\section{Dede Korkut ve Kırgız Edebiyatında Nasihat Türü Örnekleri}

Dede Korkut Hikayelerinde 30 defa kullanılan yahşı kelimesi, yakışıklı, yardımsever, insaf sahibi, cesur, klymetli, tatll, bol sulu, iyi cins, hızlı vb. anlamlarda karşımıza çıkmaktadır. Ayrıca, yahşı redifli dizelerde, normatif bir yapıyla, buyurucu bir fiil anlamıla da dikkat çekmektedir.

Kırgız Edebiyatında nasihat türünde yazılan eserlere ve nasihat içerikli metinlere baktığımızda, Kitâb-1 Dede Korkut içinde yer alan yahşı redifli nasihat dizeleriyle örtüştüğü görülmektedir. Kazılık Koca Oğlu Yigenek Boyu'nda Yigenek, dayısına düşünde şöyle soylamaktadır:

Kese kese yimege yahnı yahşı

Keser günde ser çeşme yügrük yahş1

Dayim geldüginde tursa devlet yahşı

Bildügin unıtmasa 'akıl yahşı

Karımından dönmese kaçmasa erlik yahş1 (Ergin, 1997: 203)

Yukarıdaki dizelerde, öğüt verme şekli dikkat çekicidir. Öğütlerin 'yahşı (iyi)' redifiyle verilmesi, 'iyi' kavramıla buyиrucu bir dil kullanılmak istenmesinden kaynaklanmış olsa gerektir. Zira, er (yiğit) olan kişide olması gereken, düşmandan korkup kaçmama özelliğidir. Dolayısıyla, er kişi düşmandan kaçmamalıdır; akıl, bildiğini unutmamalıdır; devlet ebed müddet olmalıdır; kesecek günde ser-çeşme yügrük, kese kese yemek için yahni olmalıdır. Yani bu dizelerde iyilik kavram1, ahlak felsefesinin pratik boyutuna göre buyurucudur. Olsa da olur; olmasa da olur; türünden bir nasihat/ögüut değildir. Şayet böyle olsayd1, Türkçedeki yig kelimesi tercih edilebilirdi.

Yukarıda verilen dizelerdeki üslup ve şekil, çağdaş Kırgız Edebiyatı nasihat türü örneklerinde de görülmektedir. Kırgız Edebiyatının okuma yazma bilen halk şairlerinden Togolok Moldo, Sanat başlıklı şiirinde, Dede Korkut'ta yer alan ve yukarıda örneğini verdiğimiz nasihat verme şeklinin benzerini karşımıza çıkarmaktadır. cakşı (yahşı) redifli dizelerde verilen nasihatler, Dede Korkut'ta da benzer redif düzeniyle verilmiştir. Kırgız Edebiyatındaki cakşı redifli öğüt ifadelerinde cakşı kelimesinin anlamı, Dede Korkut'taki gibi normatif yani buyurucu niteliktedir. Bu dizlerde verilen nasihatlerin, pratik hayatta karşılıkları bulunmakta, yaratılışın gereklerini (ahlak) yerine getirmek için, yani felsefi dilde iyiye ulaşmak için olması gerekenleri sıralamaktadır.

1925 y1lında Değişim ve Nasihat manzumeleri kısaltılarak birleştirilen ve Moskova'da basılan, Manas Destanı'nın önemli ve büyük bir varyantını yazan Togolok Moldo, aşağıdaki dizelerde cakşı redifli nasihatler söylemiştir:

Cigitterge kız cakşı (Yiğitlere kız iyidir)

Münüşkörgö kuş cakşı (Avcı için kuş iyidir)

Tamaktın babın keltirgen, (Yemeğin tadını veren)

Tattuu kılgan tuz cakşı (Tatlı yapan tuz iyidir)

Sarañdık k1lgan bakıldan (Cimrilik eden vekilden)

Sakılıḳ kılgan mart cakşı (İktisat eden cömert iyidir)

....

Kadırın tapkan er cigit (Kadrini bulan er iyidir)

Karı caşka ten cakşı (Yaşl1-gence denk iyidir)

Togolok Moldo 'Sanat' (Moldo, 1970: 112)

19. asırda Kırgızların Manasçısı ve halk şairlerinden biri olan Aytıke, Kim Cakşı adlı 
şiirinde cakşı redifli nasihatler söylemiştir: ${ }^{2}$

Moldolor üçün din cakşı (Mollalar için din iyidir)

Bakşılar üçün cin cakşı (Bahşılar için din iyidir)

Kempirler üçün çal cakşı (Kocakarılar için ihtiyar adam iyidir)

Dıykandar üçün dan cakşı (Çiftçiler için mahsul iyidir)

Kadırın bilip bakkanga, (Değerini bilip besleyene)

Koroo koroo mal cakşı. (Ağıl ağıl mal iyidir)

Kırgız Edebiyatında irticalen söylediği lirik ve felsefî şiirleriyle diğer şairlerden farklı bir yerde olan Barpı Alıkulov, cakşı redifli ve nasihat içerikli şiirler söylemiştir:

Dosun dosu menen kılat karşı (Dostu, dostuyla karşı karşıya getirir)

Uşaķtın uuday tilin bilgen cakşs (Dedikodunun zehirli dilini bilen iyidir)

Barpı Alıkuluulu 'Uşakçı (Alıkulov, 1995: 80)

\section{Sonuç ve Öneriler}

Kırgız Edebiyatında nasihat verme şekillerinden biri olan cakşı redifli nasihatleri, 19. asırda Kırgızların Manasçısı ve halk şairlerinden biri olan Aytıke, aynı asırda irticalen söylediği lirik ve felsefî şiirleriyle diğer şairlerden farklı bir yerde olan Barpı Alıkulov, Değişim ve nasihat manzumeleri birleştirilerek 1925'te Moskova'da Nasihat adıla basılan Togolok Moldo gibi halk şairleri tarafından söylenmiştir.

Dede Korkut ile karşılaştırmalı olarak incelediğimiz nasihat şekli, Dede Korkut'ta sadece Kazılık Koca Oğlu Yigenek Boyu'nda Yigenek'in dayısına düşünde söylediği dizelerde tespit edilmiştir. Kırgız edebiyatında ise birkaç halk şairinin şiirlerinde karşımıza çıkmaktadır.

Dede Korkut ve Kırgız edebiyatı için yahşı/cakşı redifli öğütler, ahlak felsefesi bakımından buyurucu (normatif) nitelik taşımaktadır.

yahşı/cakşı kelimeleri yerine, 'daha iyi' anlamını yig kelimesinin kullanılmayışı, yahşı/cakşs kavramının buyurucu niteliğini, yani tercihten öte bir anlamı vermektedir düşüncesindeyiz.

Hem Dede Korkut Hikayeleri hem de Kırgız edebiyatında, söz konusu dizelerde verilen nasihatler, iyi (yahşı/cakşı) kavramını olumlu anlamda özellik olarak göstermiştir.

Dede Korkut'ta 30 defa geçen yahşı kelimesi, yahşı redifli öğüt olarak 5 kez tekrarlanmaktadır. Kırgız Edebiyatı'nda ise cakşı redifli olmak üzere, birkaç şâirin eserlerinin bazı bölümlerinde geçmektedir.

Kırgız Edebiyatı ve Dede Korkut'ta verilen yahşı/cakşı redifli nasihatlerin bir diğer ortak noktası, hayatın her alanında olması gerekenleri, yani yaratılış kurallarını (ahlak) idealize etmiş olmalarıdır.

\section{Kaynakça}

Akın, C. (2014). Yunus Emrenin Risaletü’n Nushiyyesi ve Kırgız Edebiyatında Nasihat Türü Örnekleri. Journal of Language and Literature Studies, (10).

Alıkulov, Barpı, Çıgarmalar-I.Tom (Eserler-I.Cilt). Kırgız Entsiklopediyası Başkı Redaksiyası (Kırgız Ansiklopedisi Redaksiyonu), Bişkek, 1995.

Ergin, M. (1997) Dede Korkut Kitabı I (Giriş - Metin Faksimile), Ankara: Atatürk Kültür, Dil ve Tarih Yüksek Kurumu yayınları: 169.

Hacızade, N. (1999). Dede Korkut Destanlarında Yahşi ve Yaman Kelimeleri. Uluslararası Dede Korkut Bilgi Şöleni Bildirileri, 19-21 Ekim, Ankara.

\footnotetext{
${ }^{2}$ http://ekitap.kulturturizm.gov.tr/Eklenti/13479, aytikepdf.pdf?0
} 
Moldo, T. (1970). Clgarmalarının Eki Tomduk Clynagl (Eserlerinin iki ciltlik toplamı). Cilt-I. S. 112. Frunze (Bişkek): Kırgız CCCP İlimler Akademiyası (Kırgız Sovyet İlimler Akademisi Yayınları).

Özturan, H. (2015). Ahlak Felsefesinin Temel Problemleri (Seçme metinler), , İstanbul: Nobel Yayınları.

Ulucan, M. (2012). Türk Kültür ve Edebiyatında Pend (Ö̈̆̈̈̈t) Geleneği. Prof. Dr. Mine Mengi Adına Türkoloji Sempozyumu (20-22 Ekim 2011) Bildirileri, Adana. 